\title{
Neurofibromatosis type 1 associated with pheochromocytoma and gastrointestinal stromal tumors: A case report and literature review
}

\author{
DONGFENG PAN ${ }^{1 *}$, PEIFENG LIANG ${ }^{2,3^{*}}$ and HONGYAN XIAO ${ }^{4}$ \\ ${ }^{1}$ Emergency Department; ${ }^{2}$ Department of Medical Statistics, The People's Hospital of Ningxia Hui Autonomous Region, \\ Yinchuan, Ningxia Hui Autonomous Region 750021; ${ }^{3}$ Department of Epidemiology and Biostatistics, \\ School of Public Health, Xi'an Jiaotong University Health Science Center, Xi'an, Shaanxi 710061; \\ ${ }^{4}$ Department of Pathology, The People's Hospital of Ningxia Hui Autonomous Region, \\ Yinchuan, Ningxia Hui Autonomous Region 750002, P.R. China
}

Received January 2, 2015; Accepted February 1, 2016

DOI: $10.3892 / 01.2016 .4670$

\begin{abstract}
Neurofibromatosis type 1 (NF1) is a genetic disorder associated with neurofibromin 1 (NF1) gene mutation, which generates an increased risk of variety of tumor types. The current study reports a case involving NF1, pheochromocytoma (PHEO) and gastrointestinal stromal tumors (GIST). A 56-year-old man presented with abdominal pain and polypnea. Clinical investigation revealed multiple diffuse soft-tissue lesions throughout his body, and pigmented macules on the skin. Imaging analyses revealed thoracic scoliosis, multiple subcutaneous nodules in the abdomen and trunk, and a $7.0 \times 7.7 \times 8.9-\mathrm{cm}$ oval-shaped, cystic mass in the left upper abdominal cavity. Immunohistochemical staining indicated that S-100 protein and synaptophysin were highly expressed in adrenal gland neoplasm, whilst CD117 and CD34 were highly expressed in small intestine tumors. The overall clinical and pathological finding suggested a diagnosis of NF1, giant PHEO and small intestinal stromal tumor. In addition, a literature review was conducted to identify the specific clinical features of patients with this condition. Only 11 similar cases have been reported worldwide. In the present study, paroxysmal hypertension occurred in the majority of patients, and GISTs tended to be located in the small intestine. In addition, the present study demonstrated that many of the patients had a poor prognosis. Therefore, the present study indicates that NF1-PHEO-GIST
\end{abstract}

Correspondence to: Mrs. Peifeng Liang, Department of Medical Statistics, The People's Hospital of Ningxia Hui Autonomous Region, 148 West Huaiyuan Road, Yinchuan, Ningxia Hui Autonomous Region 750021, P.R. China

E-mail: doctor_pf@126.com

${ }^{*}$ Contributed equally.

Key words: neurofibromatosis type 1, pheochromocytoma, gastrointestinal stromal tumors, case report is a special type tumor with varied clinical symptoms, which may be associated with an increased risk for poor prognosis; however, more studies are required to confirm this.

\section{Introduction}

Neurofibromatosis type 1 (NF1), which is also known as von Recklinghausen's disease, is a genetic disorder that involves autosomal-dominant mutations. The disease is characterized by skin lesions called café-au-lait spots and cutaneous neurofibromas (1). The prevalence of NF1 in general population is $\sim 1$ in 3,500 (2). NF1 is associated with mutations in the neurofibromin 1 (NF1) gene, which generate an increased risk of variety of tumor types, including benign and malignant tumors (3). Studies have suggested that $0.1-5.7 \%$ of cases of NF1 are complicated with pheochromocytoma (PHEO) (4). The incidence of PHEO is 2-8 per 1,000,000 adults (4). PHEO releases catecholamines, which results in a series of clinical manifestations that include hypertension and metabolic disorders. A total of $4-25 \%$ of patients with NF1 may also present with gastrointestinal stromal tumors (GIST) $(5,6)$, which are the most common mesenchymal tumors of the gastrointestinal tract. GISTs are considered to occur in 20-40 per million inhabitants per year $(7,8)$, and $20-50 \%$ of GISTs are localized in the small intestine, usually in the jejunum $(7,8)$.

The current study presents a case of NF1 occurring with PHEO and GIST. To the best of our knowledge, this case is extremely rare. In addition, a brief literature review is presented.

\section{Case report}

On October 23, 2013, a 56-year-old male was admitted to the Emergency Department of Ningxia People's Hospital (Yinchuan, China) for abdominal pain and fever lasting 15 days, concomitant with cough and polypnea. Upon examination, the patient was found to have multiple, diffuse soft-tissue lesions measuring $1-5 \mathrm{~cm}$ in diameter located throughout his body, in addition to diffuse pigmented macules of 2-4 cm in diameter on the skin. A rough-bordered mass of 


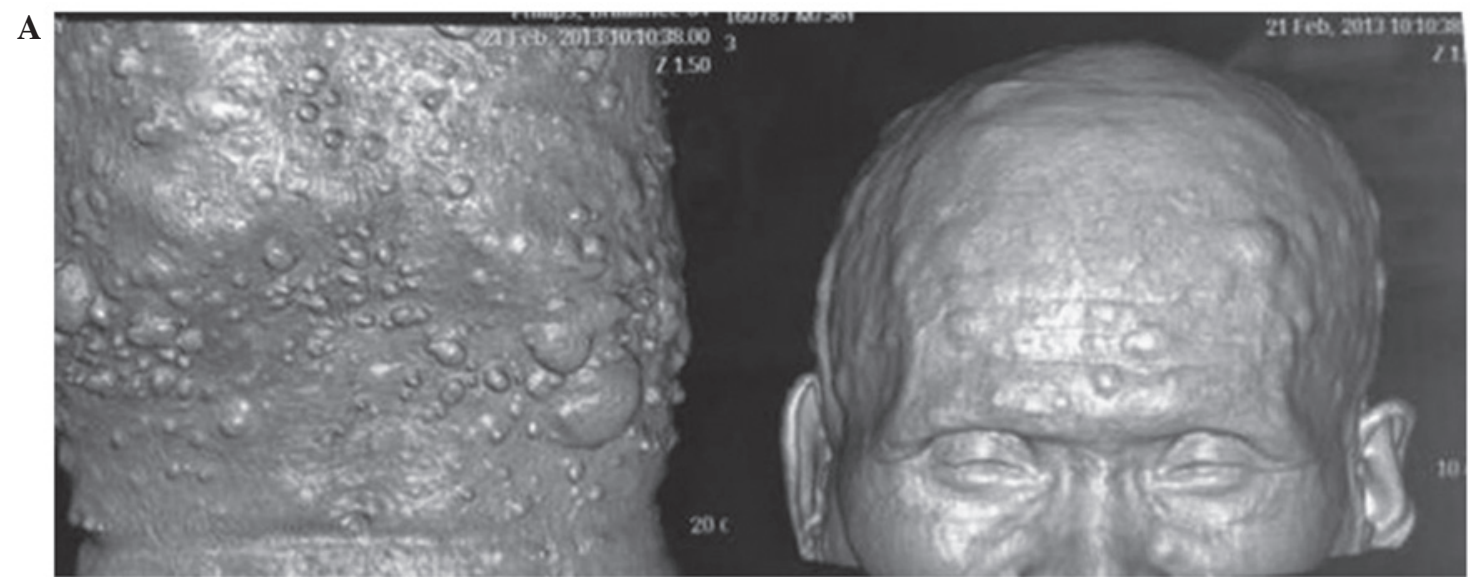

B

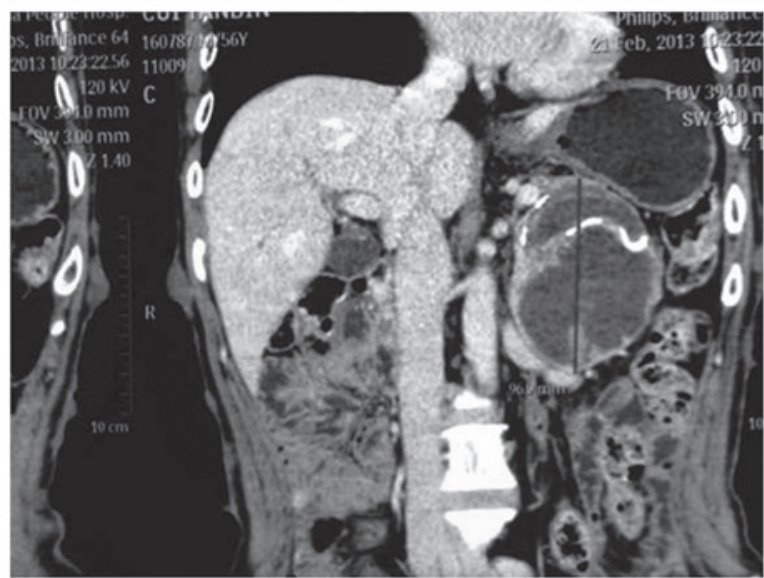

C

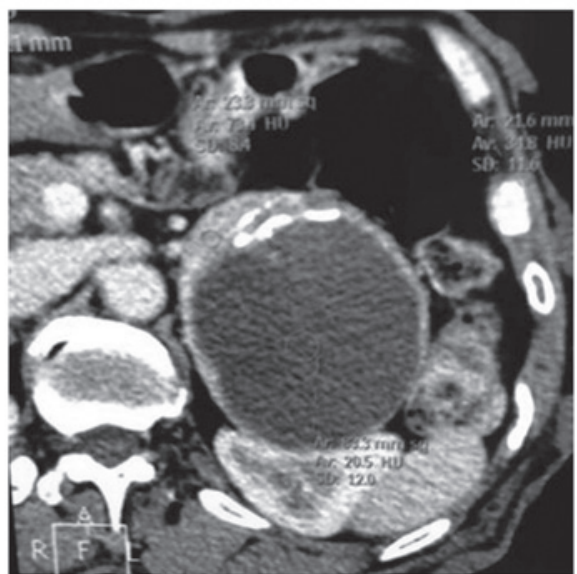

Figure 1. Computed tomography scans of the thorax, abdomen and skull. (A) Multiple nodules with soft tissue density in subcutaneous tissue of abdomen and under the scalp. (B) An oval cystic mass measuring 7.0x7.7x8.9 cm in the left upper abdominal cavity (sagittal view) with capsule wall showing obvious reinforcement; (C) oval cystic mass (axial view).

10x15 cm diameter was palpable in the upper left abdomen, and percussion pain was reported in left kidney area. No optic atrophy, papillary edema or iris Lisch nodules were found in the fundus oculi. The patient had a history of paroxysmal hypertension (up to $220 / 130 \mathrm{mmHg}$ ) for $>10$ years. In addition, his brother had a history of NF1. Digital radiographic imaging revealed thoracic scoliosis, whilst computed tomography (CT) imaging (performed using a Diamond Select Brilliance CT 16-slice scanner; Philips Medical Systems B.V., Eindhoven, The Netherlands) indicated multiple nodules with soft tissue density, as well as masses under the scalp and subcutaneous tissue of the abdomen (Fig. 1A), and an oval-shaped cystic mass measuring $7.0 \times 7.7 \times 8.9 \mathrm{~cm}$ in the left upper abdominal cavity (Fig. 1B and C).

The patient underwent surgical excision of the abdominal tumor, small intestine tumor and part of the subcutaneous nodules for pathological diagnosis. Intraoperative blood pressure fluctuated significantly and peaked at $300 / 110 \mathrm{mmHg}$. Postoperative blood pressure remained stable at $140 / 90 \mathrm{mmHg}$. Routine anti-infection and intravenous fluid therapy were administered following surgery. For histopathological examination, specimens were fixed with $10 \%$ formalin, embedded in paraffin and stained with hematoxylin and eosin $(\mathrm{H} \& \mathrm{E}) . \mathrm{H} \& \mathrm{E}$ staining of the abdominal and trunk subcutaneous nodules indicated that the tumor was composed of loose spindle cells, with little, lightly stained cytoplasm, and thin, wavy nuclei, and the cells were embedded in a fiber-like matrix (Fig. 2A).

The resected tumor from the adrenal gland was grey-red and measured $7.0 \times 7.8 \times 9.0 \mathrm{~cm}$ in size. $\mathrm{H} \& \mathrm{E}$ staining of the resected tumor revealed that the tumor capsule was calcified and the tumor contained areas of hemorrhage, necrosis and cholesterol clefts. The tumor cells in areas without hemorrhage and necrosis were arranged in an organoid pattern, with rich vascularity; the cells were moderately abnormal. (Fig. 2B). For immunohistochemical analysis, sections were incubated with antibodies for cluster of differentiation (CD)117 (polyclonal rabbit anti-human; dilution, 1:50; \#A4502), S-100 (polyclonal rabbit anti-human; dilution, 1:4,000; \#Z0311), Ki-67 (monoclonal rabbit anti-human; dilution, 1:200; \#7240), synaptophysin (polyclonal rabbit anti-human; dilution, 1:200; \#A010), chromogranin A (polyclonal rabbit anti-human; dilution, 1:500; \#A0430), neuron-specific enolase, cytokeratin (CK)7 (polyclonal rabbit; dilution, 1:500; \#A0575) and carcinoembryonic antigen (polyclonal rabbit anti-human; dilution, 1:500; \#M7072) for $24 \mathrm{~h}$ at $37^{\circ} \mathrm{C}$ (all purchased from Dako, Glostrup, Denmark). The immunohistochemical findings were S-100 (++), synaptophysin (++), chromogranin A (-), neuron-specific enolase (-), CK7 (-), carcinoembryonic antigen (-), Ki-67 (-), p53 (-) and CK18 (-).

The resected small intestine tumor was gray-white and measured $1.3 \times 1.3 \times 1.0 \mathrm{~cm}$. Upon $H \& E$ staining, the spindle 
A

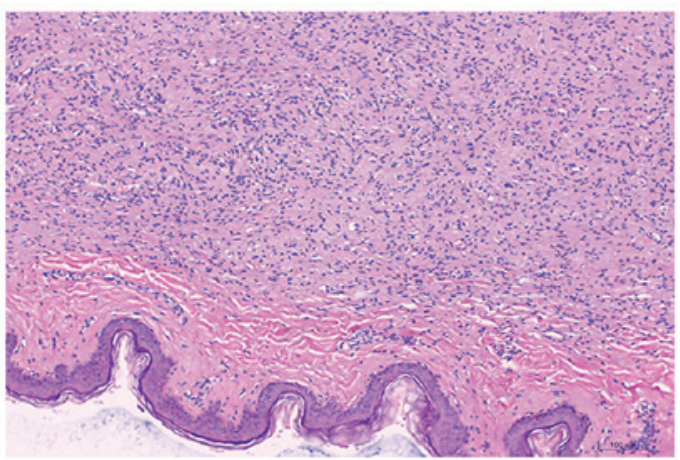

C

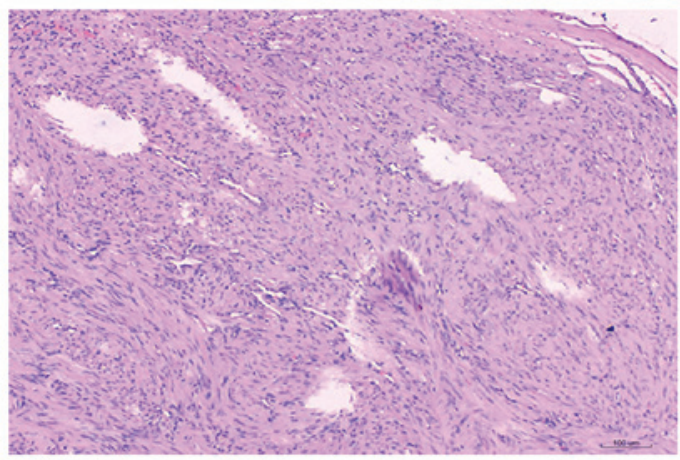

B

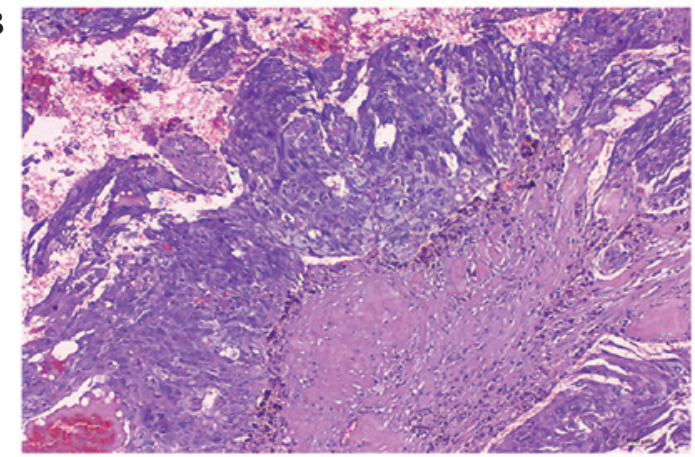

D

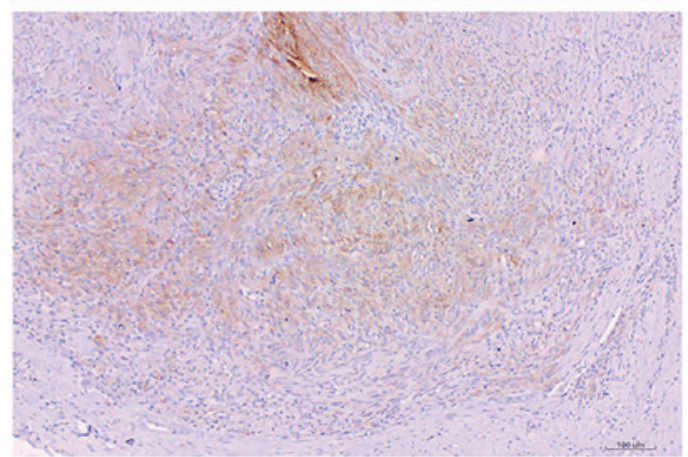

Figure 2. Histological findings (hematoxylin and eosin staining; magnification, x100). (A) Neurofibroma presented as loose spindle cells, with little and lightly stained cytoplasm, thin and wavy nuclei, and cells embedded in a fiber-like matrix. (B) Pheochromocytoma cells were multipolar, with abundant, basophilic cytoplasm and obvious nucleoli; cells were arranged in nest-like or alveolar structures and contained ample vascular fibrous tissue. (C) Small intestine tumors: Spindle cells in stomach muscularis were arranged in bundles, and the nuclei were surrounded by vacuoles. (D) Immunohistochemical staining of small intestine tumors: CD117 (++) was observed in the majority of cells, with the cytoplasm and cell membrane appearing tan colored.

cells in the stomach muscularis were found to be arranged in bundles, and the nuclei were surrounded by vacuoles (Fig. 2C). Immunohistochemical staining showed S-100 (-), CD117 (++), CD34 (++), smooth muscle actin (++) and Ki-67 (-) (Fig. 2D). Combining the clinical and pathological findings, the patient was diagnosed with NF1, giant PHEO and small intestinal stromal tumor.

During the one-year postoperative follow-up, the blood pressure of the patient remained in the normal range, and the skin nodules softened and reduced in size. No abnormal lesions were detected in abdominal CT imaging at 6 months post-surgery, and during a 2-year telephone follow-up, the patient stated that they had not experienced abnormal blood pressure or other anomalies. Written informed consent for publication of personal and medical information were obtained from the patient.

\section{Discussion}

The present study conducted a literature search for relevant articles using Pubmed (January 1950 to October 2014), OVID (1951 to October 2014), and Web of Science (1900 to October 2014). To minimize the chance of missing an important study, a manual search of the references of all articles found in our search was also performed, including any potentially eligible studies that were found using Google Scholar. The keywords were as follows: 'Neurofibromatosis', 'pheochromocytoma' and 'gastrointestinal stromal tumors'. As shown in Table I, in addition to the current patient, only 11 similar cases involving a coincidence of GIST and PHEO in NF1 have been published worldwide (9-17). A total of 10 cases reported the position of PHEO, in which 5 cases occurred in the bilateral adrenal gland; 11 cases reported the position of GISTs, in which 10 cases were located along the small intestine and 2 case was malignant; 8 cases reported clinical features, in which 6 patients had a history of hypertension, 1 patient had melena, 1 had chest pain and 1 had respiratory insufficiency; 7 cases reported clinical outcomes, in which 3 patients succumbed to pulmonary embolism, respiratory insufficiency or intestinal ischemic necrosis, respectively. NF1 is associated with a defect in the NFl gene, a tumor suppressor gene located on chromosome 17q11.2. NF1 encodes neurofibromin, which is responsible for inhibiting the activity of the p21 Ras protein, and induces a variety of clinical manifestations (18). Due to a lack of obvious mutation hotspots, clinical diagnosis of NF1 is still determined based on the criteria of the National Institutes of Health Consensus Development Conference, 1987 (19), which is documented in Table II.

NF1 has a wide range of clinical characteristics (2). The presence of multiple café au lait spots and peripheral nerve neurofibromas are prominent features. NF1 is also characterized by several developmental abnormalities, including an increased frequency of benign and malignant tumors. A descriptive analysis based on the international database of the National Neurofibromatosis Foundation (20) suggested that $4.9 \%$ of $N F 1$ cases $(n=72 / 1,479)$ are complicated by other system tumors. Other studies have suggested that $0.1-5.7 \%$ of NF1 patients have PHEO (4), whilst $4-25 \%$ of patients may have NF1 with GIST $(6,7)$. Thus, the occurrence of PHEO and GIST is rare in patients with NF1.

In a study by Zinnamosca et al (21) of 48 patients with NF-1-related PHEO (NF1-PHEO) and an average age of 


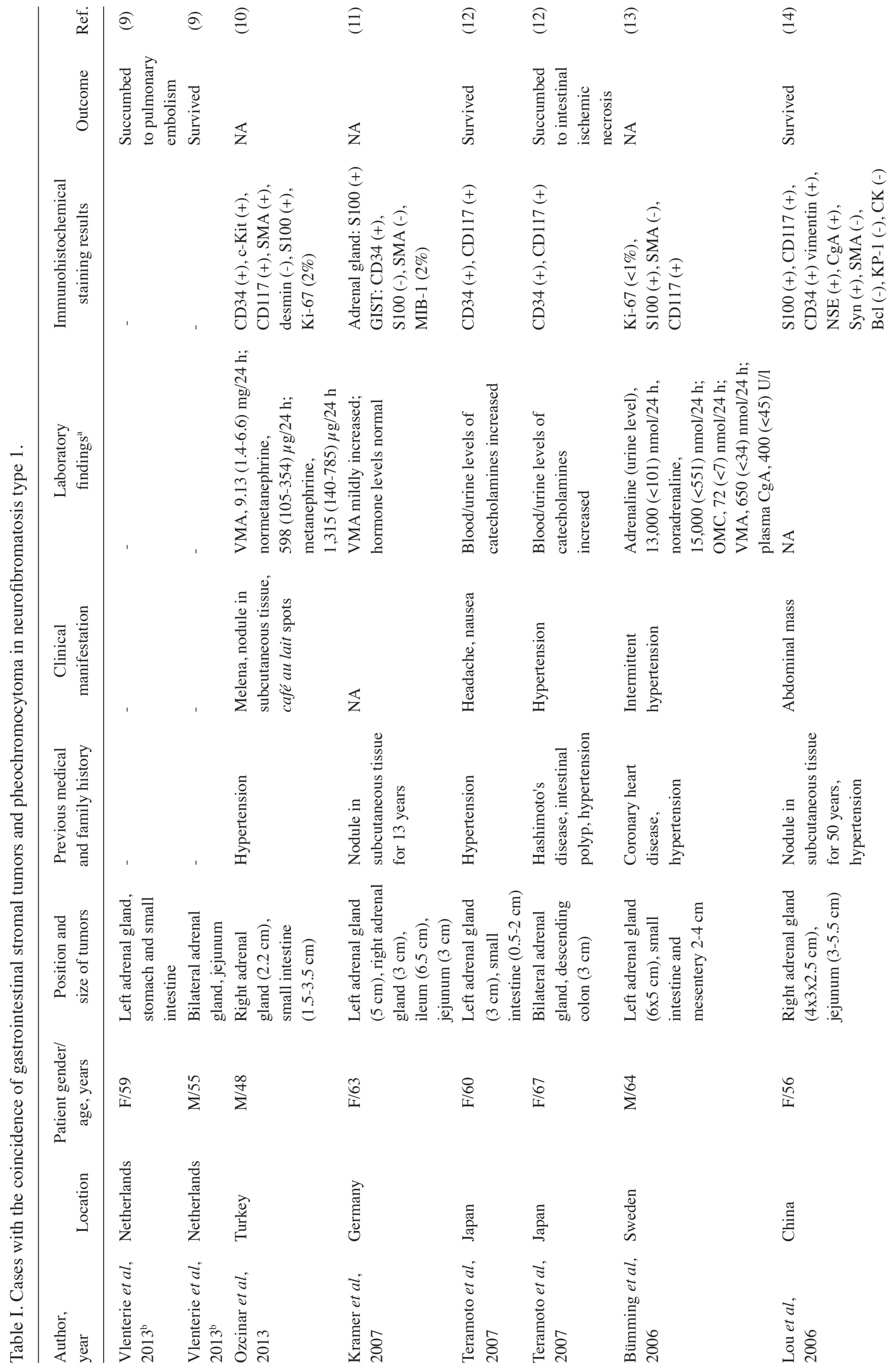



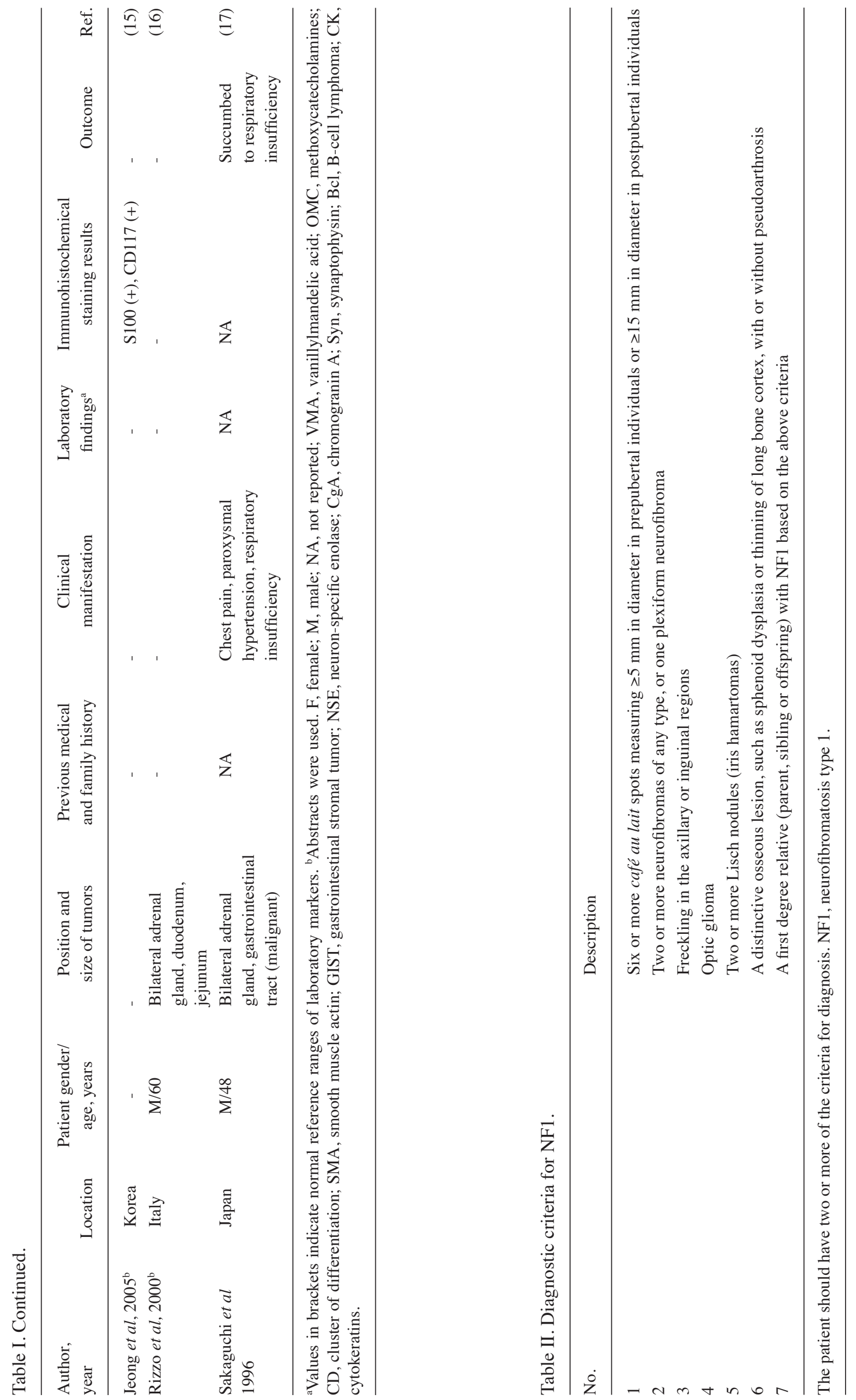
39 years, $\sim 85 \%$ of patients had single adrenal tumors, whilst $15 \%$ had bilateral adrenal tumors. In addition, $57 \%$ of patients exhibited the clinical features of high catecholamine concentration, including headache, heart palpitations, sweating and hypertension. In previous reports of clinical cases, paroxysmal hypertension was observed in the majority of NF1-PHEO patients; these results suggest that the periodic evaluation of NF1 patients with hypertension for the presence of PHEO is necessary (21-24).

The development of PHEO may be associated with the type of NF1 expression. Gutmann et al (25) demonstrated a lack of neurofibromin expression in PHEO from 6 patients with NF1, supporting the idea that neurofibromin may participate in the pathogenesis of NF1-PHEO. Additionally, reduced or absent $N F 1$ gene expression was documented in a proportion of PHEO patients without NF1. Furthermore, the majority of PHEO cases expressed predominantly the type 1 NF1 isoform (75\%), as opposed to the adrenal glands, which express predominantly type 2 NF1 (60\%) (25).

The incidence of GIST accounts for only $0.1-3.0 \%$ of all gastrointestinal tumors (26); however, $11-25 \%$ patients with NF1 also have gastrointestinal carcinoid tumors (27). Although $60 \%$ of GISTs occur in the stomach whilst only $20-30 \%$ occur in the small intestine (28), NF1-related GISTs (NF1-GIST) tend to be located in the small intestine (28). The pathogenesis of NF1-GIST is different to that of sporadic GIST. The latter, which is widely considered to involve specific KIT (CD117) or platelet-derived growth factor receptor $\alpha$ polypeptide (PDFGRA) signaling-driven tumors, is characterized by frequent allelic losses of $1 \mathrm{p}, 14 \mathrm{q}$ and $22 \mathrm{q}$, and mutations of the KIT or PDGFRA genes $(6,29)$. By contrast, mutations in KIT and PDGFRA are extremely rare events in NF1-GIST (29). Rather, cell proliferation in NF-1 GIST is associated with the activation of the Ras-mitogen-activated protein kinase pathway, which may be activated via KIT or PDGFRA in association with the inactivation of the NFI gene. Additionally, loss of heterozygosity at $14 \mathrm{q}$ and $22 \mathrm{q}$ may contribute to the relatively early phase of tumor development of NF1-GIST (30). The diagnosis of GIST primarily depends on the histopathological and immunohistochemical phenotype. One of the main characteristic of GIST is positivity for CD117 and CD34 (31,32). In the majority of the present patients with NF1-GIST, CD117 and CD34 were positive, which is conducive to confirming a diagnosis.

Surgical removal is the only definitive therapy for PHEO (33). However, it is important to note that patients who experience an inconspicuous intraoperative blood pressure drop or rapid recovery of previously low blood pressure during tumor excision have the possibility for residual tumor or metastases (33). Thus, careful monitoring of blood pressure should be conducted during surgery. In addition, surgical excision is the standard approach for GIST of $>2 \mathrm{~cm}$ in diameter or with nuclear pleomorphism as a histological feature (34). Treatment should be supplemented with imatinib mesylate for suppression of CD117 receptors and prevention of tumor recurrence or metastasis (35).

In conclusion, the current study reiterates that cases of NF1 occurring with PHEO and GIST are rare. The clinical symptoms of these cases varied; however, paroxysmal hypertension occurred in the majority of patients, and GISTs were largely located in the small intestine. The present study aims to offer guidance in the diagnosis and treatment of similar cases.

\section{References}

1. Riccardi VM: Von Recklinghausen neurofibromatosis. N Engl J Med 305: 1617-1627, 1981.

2. Friedman JM: Epidemiology of neurofibromatosis type 1. Am J Med Genet 89: 1-6, 1999.

3. Gutmann DH, Aylsworth A, Carey JC, Korf B, Marks J, Pyeritz RE, Rubenstein A and Viskochil D: The diagnostic evaluation and multidisciplinary management of neurofibromatosis 1 and neurofibromatosis 2. Jama 278: 51-57, 1997.

4. Walther MM, Herring J, Enquist E, Keiser HR and Linehan WM: von Recklinghausen's disease and pheochromocytomas. J Urol 162: 1582-1586, 1999.

5. Fung M M, Viveros O H, O'Connor D T: Diseases of the adrenal medulla. Acta Physiol 192: 325-335, 2008.

6. Miettinen M, Fetsch JF, Sobin LH and Lasota J: Gastrointestinal stromal tumors in patients with neurofibromatosis 1: A clinicopathologic and molecular genetic study of 45 cases. Am J Surg Pathol 30: 90-96, 2006.

7. Yantiss RK, Rosenberg AE, Sarran L, Besmer P and Antonescu CR: Multiple gastrointestinal stromal tumors in type I neurofibromatosis: A pathologic and molecular study. Mod Pathol 18: 475-484, 2005.

8. Cichoz-Lach H, Kasztelan-Szczerbińska B and Słomka M: Gastrointestinal stromal tumors: Epidemiology, clinical picture, diagnosis, prognosis and treatment. Pol Arch Med Wewn 118: 216-221, 2008.

9. Vlenterie M, Flucke U, Hofbauer LC, Timmers HJ, Gastmeier J, Aust DE, van der Graaf WT, Wesseling P, Eisenhofer G and Lenders JW: Pheochromocytoma and gastrointestinal stromal tumors in patients with neurofibromatosis type I. Am J Med 126: 174-180, 2013.

10. Ozcinar B, Aksakal N, Agcaoglu O, Tukenmez M, Ozemir IA, Barbaros U, Colak N and Erbil Y: Multiple gastrointestinal stromal tumors and pheochromocytoma in a patient with von Recklinghausen's disease. Int J Surg Case Rep 4: 216-218, 2013.

11. Kramer K, Hasel C, Aschoff AJ, Henne-Bruns D and Wuerl P: Multiple gastrointestinal stromal tumors and bilateral pheochromocytoma in neurofibromatosis. World J Gastroenterol 13: 3384-3387, 2007.

12. Teramoto S, Ota T, Maniwa A, Matsui T, Itaya N, Aoyagi K, Kusanagi $\mathrm{H}$ and Narita M: Two von Recklinghausen's disease cases with pheochromocytomas and gastrointestinal stromal tumors (GIST) in combination. Int J Urol 14: 73-74, 2007.

13. Bümming P, Nilsson B, Sörensen J, Nilsson O and Ahlman H: Use of 2-tracer PET to diagnose gastrointestinal stromal tumour and pheochromocytoma in patients with Carney triad and neurofibromatosis type 1. Scand J Gastroenterol 41: 626-630, 2006.

14. Luo ZM, Jin XL and Teng HH: Neurofibromatosis type I complicating interstitialoma and pheochromocytoma: A case of report. Chin J Diag Pathol 36: 140-141, 2006.

15. Jeong CY, Hong SC, Lee YJ, Jung EJ, Choi SK, Joo YT, Ha WS, Park ST and Lee JS: Multiple duodeno-jejunal GIST associated with pheochromocytoma in patients with von Recklinghausen disease. J Korean Surg Soc 69: 74-78, 2005 (In Korean).

16. Rizzo S, Bonomo S, Moser A, Bottura D, Castellini C, Mazzola F, Lauro E, Vicenzi L, Betresini B, Angeli G, et al: Bilateral pheochromocytoma associated with duodeno-jejunal GIST in patient with von Recklinghausen disease: Report of a clinical case. Chir Ital 53: 243-246, 2001 (In Italian).

17. Sakaguchi N, Sano K, Ito M, Baba T, Fukuzawa M and Hotchi M: A case of von Recklinghausen's disease with bilateral pheochromocytoma-malignant peripheral nerve sheath tumors of the adrenal and gastrointestinal autonomic nerve tumors. Am J Surg Pathol 20: 889-897, 1996.

18. Oguzkan S, Terzi YK, Cinbis M, Anlar B, Aysun S and Ayter S: Molecular genetic analyses in neurofibromatosis type 1 patients with tumors. Cancer Genet Cytogenet 165: 167-171, 2006.

19. Neurofibromatosis. Conference statement. National Institutes of Health Consensus Development Conference. Arch Neurol 45: $575-578,1988$.

20. Friedman J and Birch PH: Type 1 neurofibromatosis: A descriptive analysis of the disorder in 1,728 patients. Am J Med Genet 70: 138-143, 1997.

21. Zinnamosca L, Petramala L, Cotesta D, Marinelli C, Schina M, Cianci R, Giustini S, Sciomer S, Anastasi E, Calvieri S, et al: Neurofibromatosis type 1 (NF1) and pheochromocytoma: Prevalence, clinical and cardiovascular aspects. Arch Dermatol Res 303: 317-325, 2011. 
22. Opocher G, Conton P, Schiavi F, Macino B and Mantero F: Pheochromocytoma in von Hippel-Lindau disease and neurofibromatosis type 1. Fam Cancer 4: 13-16, 2005.

23. Erem C, Onder Ersöz H, Ukinç K, Hacihasanoglu A, Alhan E, Cobanoğlu U, Koçak M and Erdöl H: Neurofibromatosis type 1 associated with pheochromocytoma: A case report and a review of the literature. J Endocrinol Invest 30: 59-64, 2007.

24. Rocchietti March M: Type 1 neurofibromatosis and pheochromocytoma: Focus on hypertension. J Neurosci Rural Pract 3 : 107-108, 2012.

25. Gutmann DH, Geist RT, Rose K, Wallin G and Moley JF: Loss of neurofibromatosis type I (NFI) gene expression in pheochromocytomas from patients without NFI. Genes Chromosomes Cancer 13: 104-109, 1995.

26. Singer S, Rubin BP, Lux ML, Chen CJ, Demetri GD, Fletcher CD and Fletcher JA: Prognostic value of KIT mutation type, mitotic activity and histologic subtype in gastrointestinal stromal tumors J Clin Oncol 20: 3898-3905, 2002.

27. Pinsk I, Dukhno O, Ovnat A and Levy I: Gastrointestinal complications of von Recklinghausen's disease: Two case reports and a review of the literature. Scand J Gastroenterol 38 1275-1278, 2003.

28. Caterino S, Lorenzon L, Petrucciani N, Iannicelli E, Pilozzi E, Romiti A, Cavallini M and Ziparo V: Gastrointestinal stromal tumors: Correlation between symptoms at presentation, tumor location and prognostic factors in 47 consecutive patients. World J Surg Oncol 9: 13, 2011.
29. Maertens O, Prenen H, Debiec-Rychter M, Wozniak A, Sciot R, Pauwels P, De Wever I, Vermeesch JR, de Raedt T, De Paepe A, et al: Molecular pathogenesis of multiple gastrointestinal stromal tumors in NF1 patients. Hum Mol Genet 15: 1015-1023, 2006

30. Yamamoto H, Tobo T, Nakamori M, Imamura M, Kojima A, Oda Y, Nakamura N, Takahira T, Yao T and Tsuneyoshi M: Neurofibromatosis type 1-related gastrointestinal stromal tumors: A special reference to loss of heterozygosity at $14 \mathrm{q}$ and 22q. J Cancer Res Clin Oncol 35: 791-798, 2009.

31. NovelliM,RossiS,Rodriguez-JustoM,TaniereP,SeddonB,Toffolatti L, Sartor C, Hogendoorn PC, Sciot R, Van Glabbeke M, et al: DOG1 and CD117 are the antibodies of choice in the diagnosis of gastrointestinal stromal tumours. Histopathology 57: 259-270, 2010.

32. Miettinen M, Majidi M and Lasota J: Pathology and diagnostic criteria of gastrointestinal stromal tumors (GISTs): A review. Eur J Cancer 38: S39-S51, 2002.

33. Bruynzeel H,Feelders RA, Groenland THN, van den Meiracker AH, van Eijck CH, Lange JF, de Herder WW and Kazemier G: Risk factors for hemodynamic instability during surgery for pheochromocytoma. J Clin Endocrinol Metab 95: 678-685, 2010.

34. ESMO/European Sarcoma Network Working Group: Gastrointestinal stromal tumors: ESMO Clinical Practice Guidelines for diagnosis, treatment and follow-up. Ann Oncol 23 (Suppl 7) 23: vii49-vii55, 2012.

35. Shinomura Y, Kinoshita K, Tsutsui S and Hirota S: Pathophysiology, diagnosis and treatment of gastrointestinal stromal tumors. J Gastroenterol 40: 775-780, 2005. 